\title{
Biometry of the crystalline lens in early-onset diabetes
}

\author{
John M Sparrow, Anthony J Bron, Nicholas A Phelps Brown, H A W Neil
}

\begin{abstract}
Lenticular biometry on non-cataractous lenses has been studied by means of Scheimpflug photography and digital image analysis in $\mathbf{1 5 3}$ patients with early-onset insulin-dependent diabetes and 153 non-diabetic controls. Anteroposterior axial lens thickness, cortical thickness, nuclear thickness, anterior and posterior lenticular curvatures, and anterior chamber depth were assessed. Highly significant differences between the lenses of the diabetic subjects and non-diabetic controls were found. After the effect of age had been accounted for within the diabetic subgroup, diabetic duration was found to be a highly significant determinant of lens dimensions, such that age-related dimensional changes for various biometric parameters were accelerated by between $52 \%$ and $121 \%$ after the onset of diabetes. Because the diabetic duration of the early-onset diabetic subjects studied in this work was accurately known, this report is the first in which a precise assessment of the effect of 'true' diabetic duration on lens biometry has been possible.
\end{abstract}

The crystalline lens of the eye is the only human organ which undergoes a steady increase in size due to growth throughout the life of the individual..$^{1-3}$ Mitosis in the pre-equatorial lenticular epithelium provides a constant supply of new lens fibres, which are added externally to earlier generations of fibres. ${ }^{4}$ While accretion of new fibres continues, older generations of fibres compact within the deeper layers of the lens substance. ${ }^{35}$ Anteroposterior lens growth is proportionally greater than equatorial growth, so the front and back curves of the lens steepen (radii of curvature decrease) with increasing age. ${ }^{6}$

The crystalline lens of the eye is affected by the diabetic state in a number of ways. The anterior clear zone (first zone of discontinuity) has been noted to be enlarged in young diabetics, ${ }^{7}$ and lenses of diabetic patients are larger than those of non-diabetics, after the effect of age has been accounted for ${ }^{8}$ Diabetics are in addition at risk for the development of cataractous changes, ${ }^{9-16}$ this risk being especially obvious in younger diabetics. ${ }^{12} 13$ True juvenile diabetic cataract is fortunately not common and is associated with diabetes which is metabolically severely out of control. ${ }^{17} 18$ This type of cataract probably has a specific mechanism, and may occasionally be reversible if the blood sugar concentration is kept normal. ${ }^{19}$

Diabetes therefore affects the lens in a number of important ways. Previous studies have not differentiated between early and late onset diabetes, and the effects of 'true' diabetic duration have therefore not previously been assessed. The present study examines lens biometry in relation to early-onset insulin-dependent diabetics and controls.

\section{Material and methods}

\section{SUBJECTS}

One hundred and fifty-three diabetic subjects (96 male) were recruited from general diabetic clinics, a paediatric diabetic clinic, ocular diabetic clinics, and from a population survey of diabetics. Eligible subjects had early-onset insulin-dependent diabetes, defined as diabetes requiring insulin treatment from initial diagnosis, with age at onset being 30 years or less. Recruitment was stratified for age and duration of diabetes. An equal number of control subjects were recruited (79 male), mainly from a population based ocular survey, supplemented by subjects from eye hospital clinics and an ophthalmic casualty department. Controls were included if they had no history of diabetes or impaired glucose tolerance, and a non-fasting whole venous blood glucose of less than $7 \cdot 8 \mathrm{mmol} / 1 .{ }^{2021}$

Individual eyes of diabetics and controls were included if the lenses were non-cataractous, had normal anterior ocular segments, and vision sufficiently good for the eye to hold fixation during Scheimpflug photography. Cataractous lenses were excluded because such lenses may have abnormal biometry, ${ }^{22}{ }^{23}$ though the following minor opacities as defined by the Oxford clinical cataract classification and grading system ${ }^{24}$ were permitted: nuclear brunescence and white nuclear scatter up to and including grade 2, spoke opacities and waterclefts of grade 1 , and isolated vacuoles, retrodots, and focal dots. No anterior or posterior subcapsular opacities were permitted, as subcapsular opacities were specifically known to be associated with reduced lens size. ${ }^{22}$ There were thus a total of 597 eyes eligible for study in the 306 subjects; 299 were right eyes and 298 were left eyes.

The study was approved by the Central Oxford Research Ethics Committee (ref. no. 1211), and informed consent was obtained from participants.

\section{PROCEDURE}

Subjects were recruited to the study by the primary investigator (JS). At the time of their assessments a brief medical history was taken and Snellen visual acuity determined. After the anterior chamber depth had been checked and the presence of iris supported intraocular lens implants excluded, the subject's pupils were 
Figure 1 Frequency distribution of the ages of
male and female subjects.

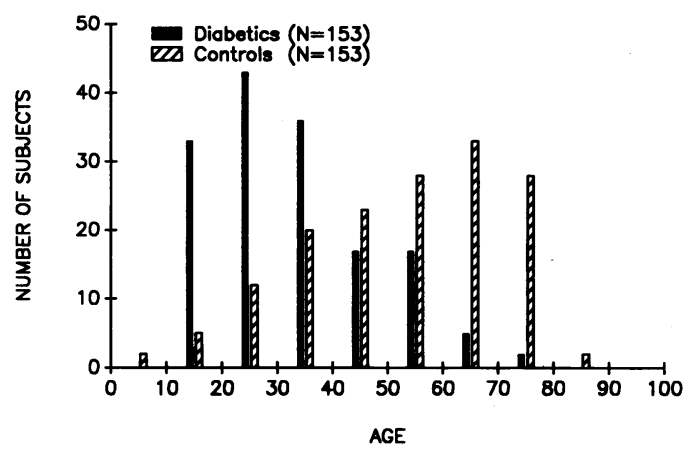

dilated with tropicamide eyedrops $1 \%$ and phenylephrine eyedrops $10 \%$, repeated if necessary.

After pupillary dilatation the crystalline lens was examined at a slit-lamp biomicroscope to exclude cataractous changes as described above. Scheimpflug slit-image photography with a Brown Scheimpflug camera ${ }^{25-27}$ was then performed, and the photographic images were subjected to digital image analysis by an image analysis system developed by the authors.

Measurements obtained from this system are uncompensated for optical distortions produced by the Scheimpflug camera optics and the corneal and crystalline lenticular magnifications, though separate horizontal and vertical calibration was used for curvature measurements. ${ }^{28}$ Anteroposterior biometry (lens thickness, cortical thickness, nuclear thickness, anterior clear zone thickness, and anterior chamber depth) were all measured by a standard method using a linear density trace running down the axis of the Scheimpflug photograph, measurement being facilitated by simultaneous display of both the density trace and the image on adjacent computer screens. Anterior and posterior lens curvatures were measured by defining three points on the curve, the computer program then working out the radius of curvature (calibrated horizontally and vertically).

\section{STATISTICAL METHODS}

Biometric measurements were in general obtained from both eyes, though certain patients contributed measurements on only one eye. A preliminary analysis was performed by plotting the biometric data against age and performing simple linear regression of biometry against age for the diabetic and non-diabetic groups. To take account of the within-subject inter-eye correlation, the intra-class correlation model

TABLE 1 Age by diabetic duration of the early onset diabetes study population

\begin{tabular}{|c|c|c|c|c|c|c|}
\hline \multirow[b]{2}{*}{ Age } & \multicolumn{6}{|c|}{ Diabetic duration (years) } \\
\hline & 0 to $<10$ & 10 to $<20$ & 20 to $<30$ & 30 to $<40$ & 40 to $<50$ & Total \\
\hline 0 to $<10$ & 0 & - & - & - & - & 0 \\
\hline 10 to $<20$ & 22 & 11 & - & - & - & 33 \\
\hline 20 to $<30$ & 20 & 16 & 7 & - & - & 43 \\
\hline 30 to $<40$ & 5 & 17 & 11 & 3 & - & 36 \\
\hline 40 to $<50$ & - & 6 & 7 & 3 & 1 & 17 \\
\hline 50 to $<60$ & - & - & 6 & 6 & 5 & 17 \\
\hline 60 to $<70$ & - & - & - & 4 & 1 & 5 \\
\hline 70 to $<80$ & - & $=-$ & - & - & 2 & 2 \\
\hline Total & 47 & 50 & 31 & 16 & 9 & 153 \\
\hline
\end{tabular}

0 to $<10=$ up to but excluding 10 years, and so on. was employed in the analysis. ${ }^{29-30}$ All dependent variables were continuous and approximately normally distributed. The analysis took the form of a multiple linear regression analysis with groups (factors), the biometric measures being used as dependent variables in a series of model fitting exercises. Age was therefore treated as a co-variate, compensating for the imperfect age matching of the diabetic and non-diabetic groups where these were being compared.

Significant effects were sought for various patient characteristics. Three series of analyses were performed, the first included all subjects $(n=306)$, the second included only the early onset diabetics $(n=153)$, and the third included only the non-diabetic controls $(n=153)$. Terms were included into the models in a fixed, predetermined order, and this order is adhered to in the summary table of the analysis (Table II). Certain terms were always included in the model (obligatory terms), while others were included only if they were found to be significant at the $5 \%$ level (optional terms). Where very powerful effects were found for continuous independent variables (namely, age and duration of diabetes) multiple linear regression slopes for these variables are reported. In this analysis the age slope derived from the control group was imposed on the regression model for the diabetic group, the duration slope therefore being exclusively the additional effect of duration over and above the effect of age. (This method circumvents the statistical problems associated with the fact that age and duration are partially correlated variables.) The analysis was performed by the Generalised Linear Interactive Modelling (GLIM) System of the Numerical Algorithms Group on the Oxford University mainframe computer (VAX cluster).

\section{Results}

The age distributions of the diabetics and controls are shown in Figure 1, and the age by duration distributions of the diabetics appear in Table 1. Figures 2 to 8 show the results of the preliminary regression analysis of biometry against age. These graphs illustrate that age was an important determinant of the biometry of the anterior ocular segment (an exception to this was the anterior clear zone thickness). Further it can be seen from these graphs that the regression lines for the early onset diabetics differed from those of the non-diabetics. In general the lenses of diabetics appeared larger than those of nondiabetics (Fig 2), this effect being more obvious in the cortex (Fig 3) than in the nucleus (Fig 4). The anterior clear zone of the diabetics was also considerably larger than that of the non-diabetics (Fig 5). The larger diabetic lenses were associated with shallower anterior chambers (Fig 6), and with steeper curvatures (smaller front (Fig 7 ) and back (Fig 8) radii of curvature).

Formal analysis confirmed these preliminary findings. A summary of $p$ values from the formal analysis appears in Table 2. From the allsubjects analysis (306 subjects) in this table it is apparent that age was a powerful determinant of biometry. These effects were such that older age was associated with larger lens dimensions, 


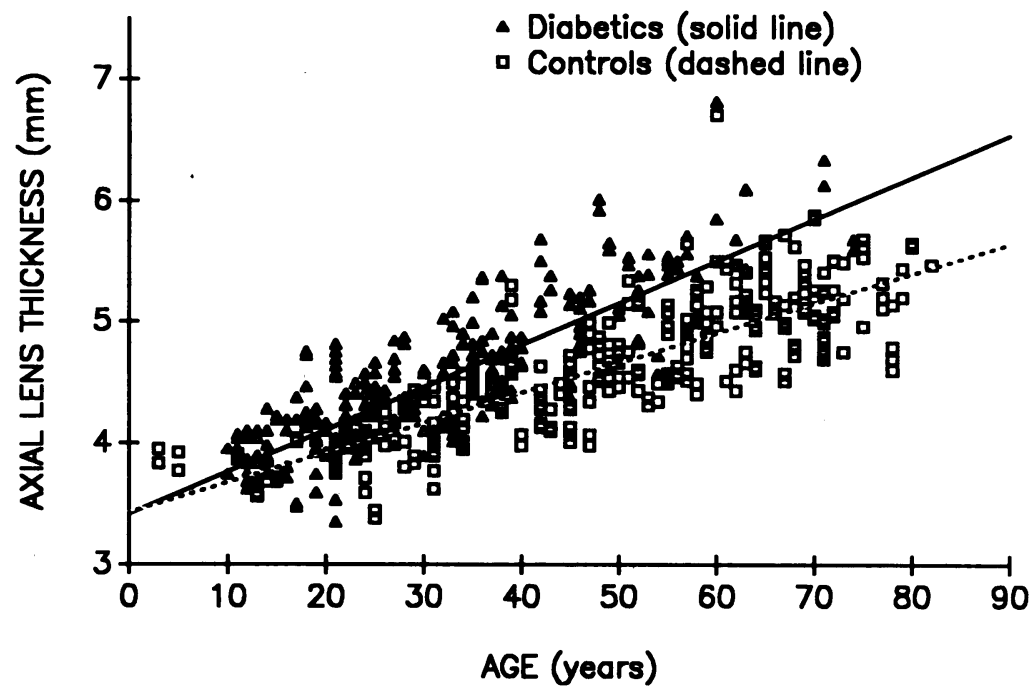

Figure 2 Plot of anteroposterior axial lens thickness in mm units derived from image analysis of Scheimpflug photographs, against age in years. Separate linear regression lines for diabetics and controls.

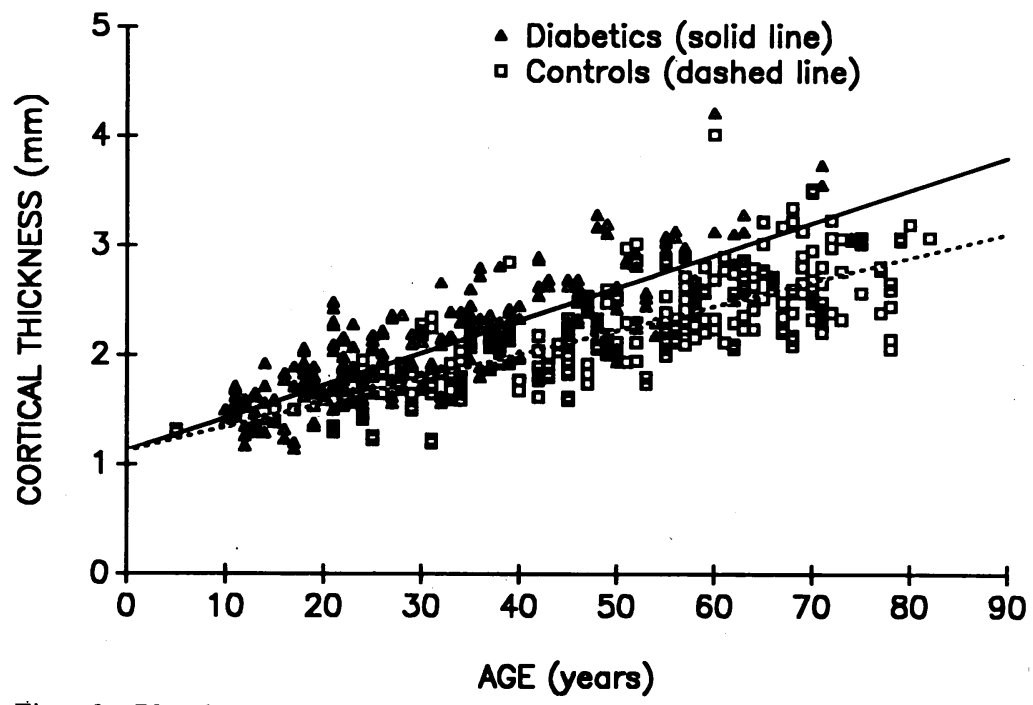

Figure 3 Plot of anteroposterior cortical thickness of the lens in mm units derived from image analysis of Scheimpflug photographs, against age in years. Separate linear regression lines for diabetics and controls.

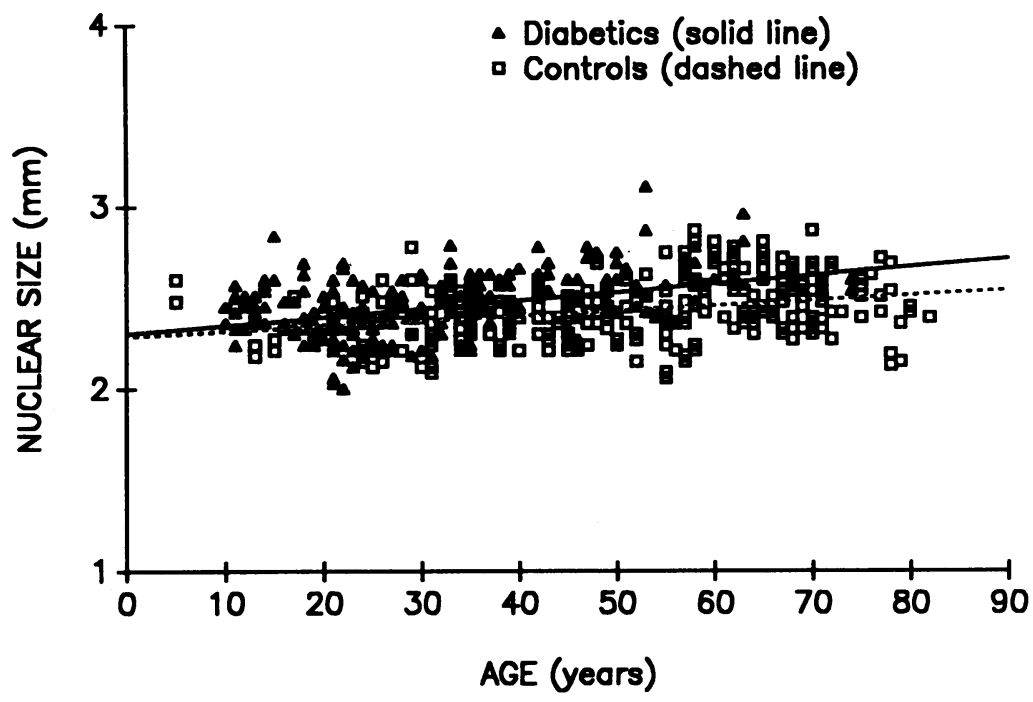

Figure 4 Plot of anteroposterior nuclear size of the lens in mm units derived from image analysis of Scheimpflug photographs, against age in years. Separate linear regression lines for diabetics and controls. shallower anterior chambers, and steeper surface curvatures. Diabetic status was also a powerful determinant of biometry, with diabetic lenses being larger, being associated with shallower anterior chambers, and having steeper front and back curvatures than those of controls. The significant age by status interactions (Age. Sta) for axial lens thickness, cortical thickness, and anterior chamber depth were such that the slopes of the regression lines against age for the diabetics were significantly steeper than those of the controls (see Figs 2, 3, 5). The effect of sex was such that female sex was associated with decreased cortical thickness, with increased nuclear size, and with decreased anterior chamber depth.

In the early onset diabetes subgroup (153 subjects) age was powerfully associated with biometry. Diabetic duration was generally also a powerful determinant of biometry. Female sex was associated with decreased cortical thickness. Higher daily insulin dose was associated with reduced nuclear size and increased anterior clear zone thickness. The presence of diabetic retinopathy was associated with a larger lens nucleus, with increased anterior clear zone thickness and with steeper surface curvatures.

In the non-diabetic controls subgroup (153 subjects) age was again powerfully associated with biometry. Among the controls female sex was associated with smaller cortical thickness and larger nuclear size.

The linear regression slope for age alone in the non-diabetic controls subgroup, and the multiple linear regression slope for duration in the diabetic subgroup (effect of age fixed to that of the control group), are displayed in Table 3 . Also displayed are associated $\mathrm{p}$ values from the intraclass correlation analysis, and the duration/age slope ratios. (Anterior clear zone was excluded because age and diabetic duration were not powerful determinants of this feature.) These duration slopes indicate the additional effect of diabetic duration over and above the normal effect of age. For the various biometric parameters in Table 3 the ratio of the slopes of age and duration demonstrate that the independent effect of diabetic duration per year on biometry is between $52 \%$ and $121 \%$ of the effect of age per year, with the effect on overall lens thickness being $68 \%$ and that on anterior chamber depth being $100 \%$.

\section{Discussion}

The present work confirms earlier findings that the diabetic state profoundly affects the biometry of the crystalline lens, ${ }^{78}$ and it has extended this knowledge in terms of the biometry of the anterior ocular segment as a whole in noncataractous early onset diabetics and non-diabetic controls. In addition other patient characteristics have been examined, and it is clear from the results of this study that duration of diabetes is of paramount importance in the determination of anterior segment biometry in early onset diabetics. The data show that in these diabetics, from the time of diagnosis, the rate of change of lenticular biometry per year increases markedly. Other subject features (sex, daily insulin dose, 


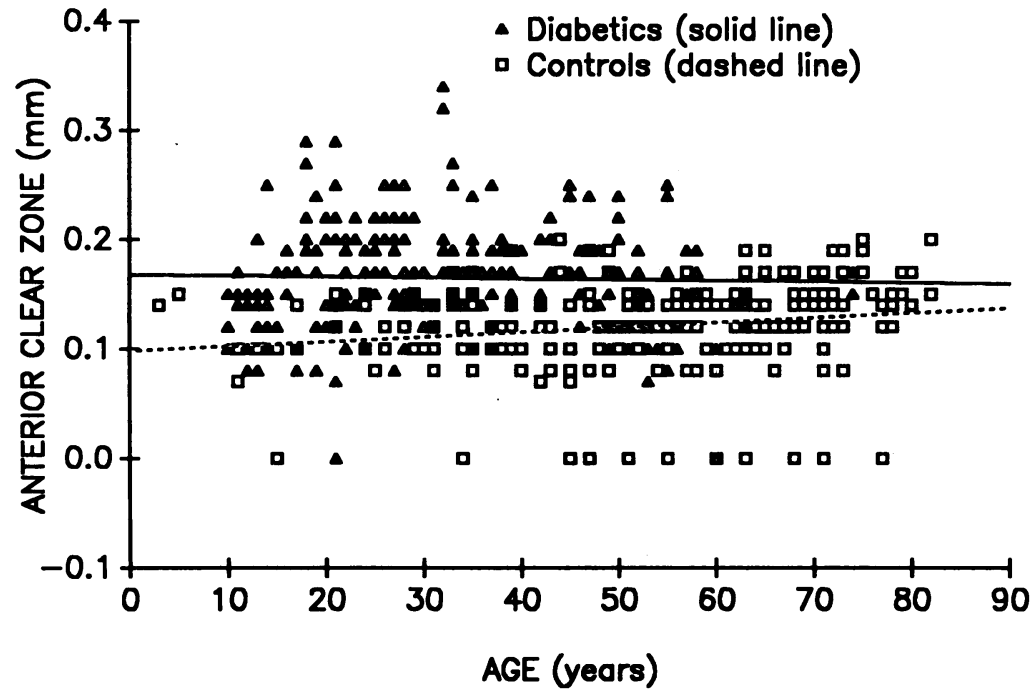

Figure 5 Plot of anterior clear zone thickness of the lens in mm units derived from image analysis of Scheimpflug photographs, against age in years. Separate linear regression lines for diabetics and controls.

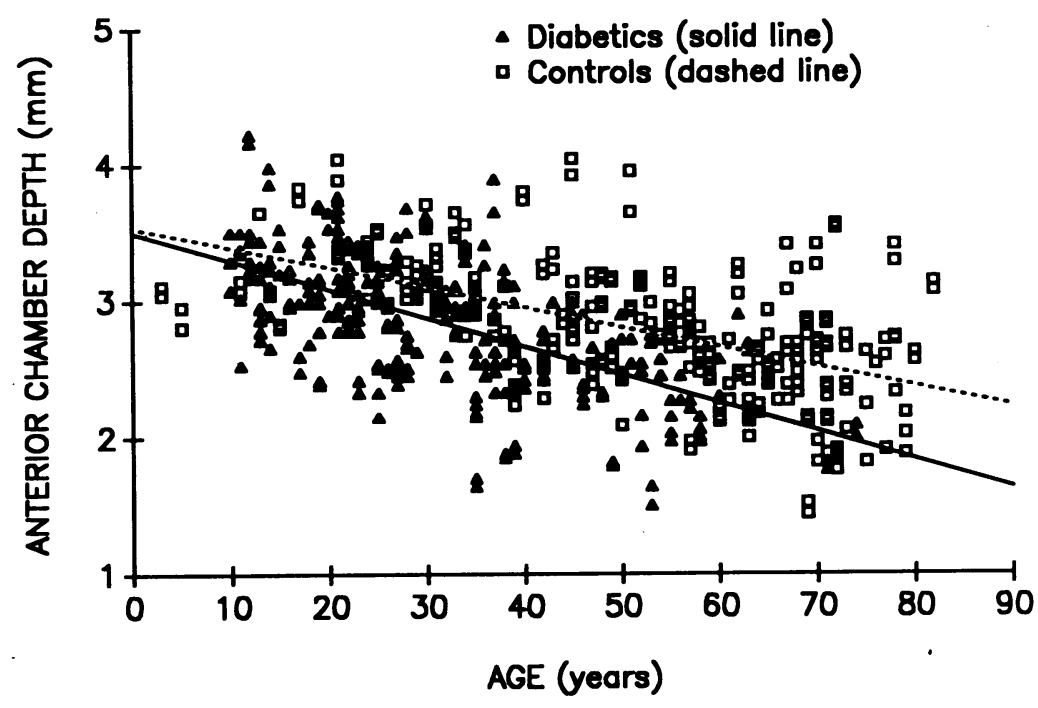

Figure 6 Plot of axial anterior chamber depth of the eye in $\mathrm{mm}$ units derived from image analysis of Scheimpflug photographs, against age in years. Separate linear regression lines for diabetics and controls.

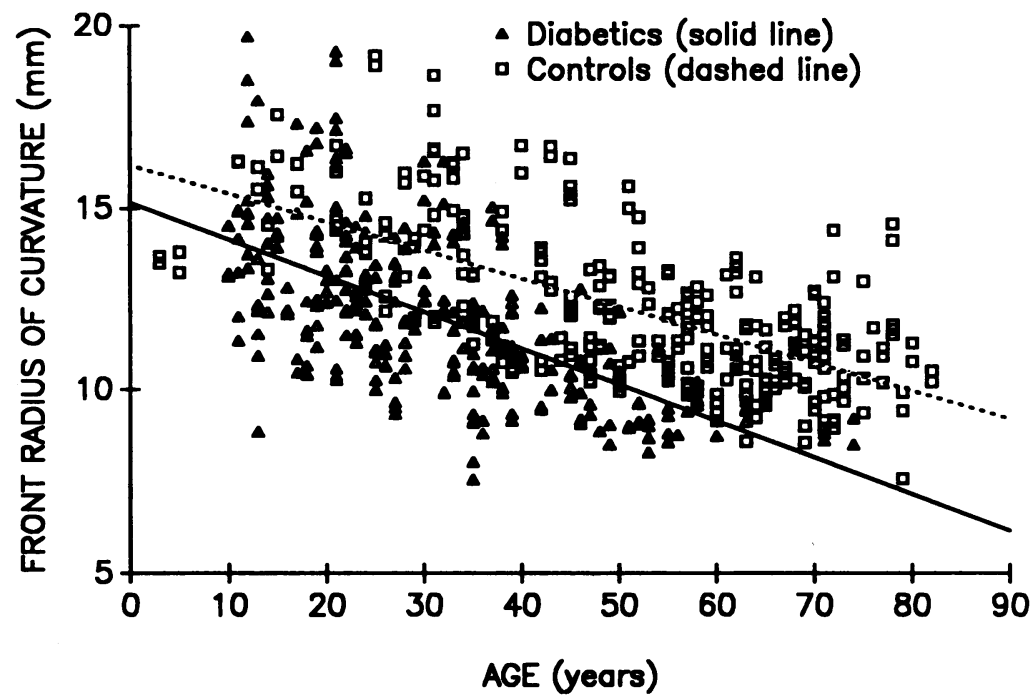

Figure 7 Plot of front radius of curvature of the lens in mm units derived from image analysis of Scheimpflug photographs, against age in years. Separate linear regression lines for diabetics and controls. and presence of diabetic retinopathy) were of variable importance.

The anterior clear zone is of special interest because it behaves independently of the other zones of the lens. This zone has attracted attention in health ${ }^{32}$ and disease ${ }^{33}$, being reduced in cataractous lenses ${ }^{22} 23$ and increased in lenses of diabetics. ${ }^{78}$ In the present work the finding of an increased anterior clear zone thickness in diabetes is confirmed, though no relationship with duration has been found. This zone appears to represent a phase in the maturation of young cortical fibres, which sink through it into the deeper cortex as they mature. It has been suggested that the size of this zone reflects the rate of growth of the lens at any particular time. ${ }^{33}$ If maturation takes a fixed period, then in a situation of accelerated 'growth' more (or larger) fibres would be in this phase of maturation, and the zone would therefore become wider. The converse would apply in lenses where growth was slowed or halted, when the zone could be expected to shrink or even disappear completely. Brown and Tripathi ${ }^{22}$ have shown that the clear zone is reduced or absent in lenses with cataracts, posterior subcapsular cataracts in particular, and further that reduction of the clear zone is associated with a 'small for age' axial lens size. Perkins ${ }^{23}$ has corroborated these findings by a simple optical method, and has shown that lenses with early cortical and posterior subcapsular cataracts have reduced overall anteroposterior thickness, and that $60 \%$ of early cataracts of all types have a deficient anterior clear zone.

The changes in lens dimensions in diabetes may result from an abnormality in the growth of the lens. From the mechanical point of view three possible explanations exist in relation to altered growth characteristics. The rate of new fibre formation might be increased, with more maturing fibres in the anterior clear zone, and more mature fibres making up the increased bulk of the lens. This 'hyperplastic' model would fit with the findings in the present work, in that the dimensional changes as well as the effect of diabetic duration are natural consequences of such a model. Alternatively the number of new fibres produced might be normal, with individual fibres being increased in size. This 'hypertrophic' model could explain the dimensional changes and duration related effects equally well. The hypertrophic change might be limited to the metabolically active superficial nucleated fibres, which would explain the observed events, with hypertrophic fibres, once enlarged, remaining so. A combination of the above two mechanisms might also exist, and there is evidence that cell size and DNA synthesis can be independently regulated by appropriate combinations of cellular growth factors and growth inhibitors. ${ }^{34}$ The third possibility in relation to altered 'lens growth' is a reduction in central compaction of mature lens fibres. There may be some support for this notion in the fact that the ratio of the slopes for the effects of duration and age is the highest for nuclear size (Table 3). This may imply less efficient central fibre packing in diabetes. Brown et $a l^{35}$ could not demonstrate any statistically significant difference in superficial cortical fibre size between diabetics and 


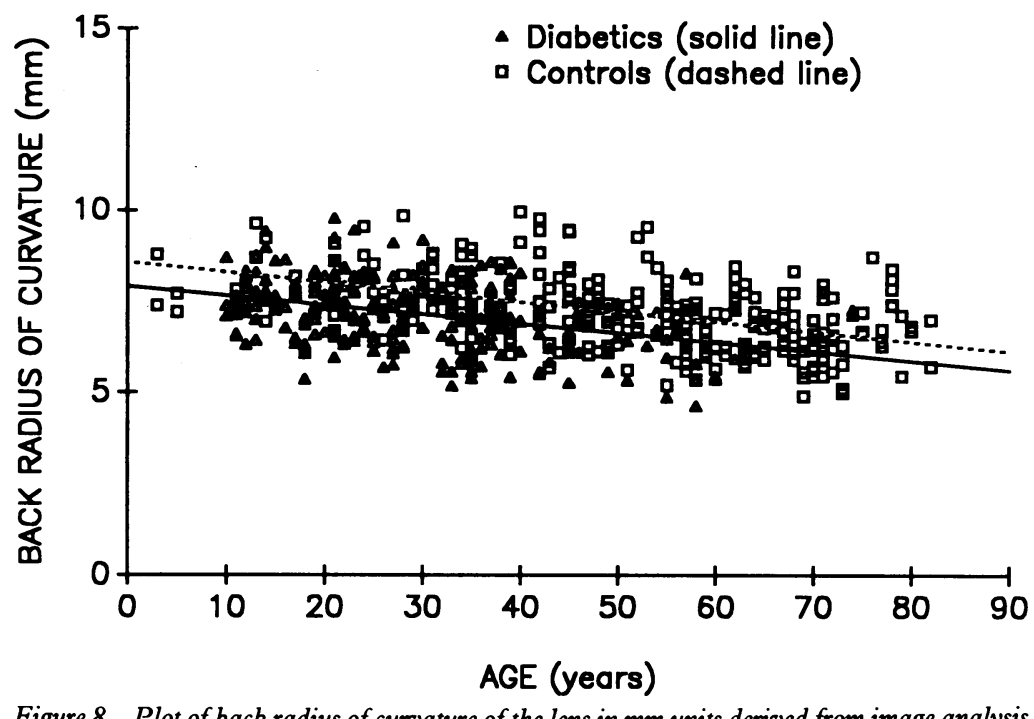

Figure 8 Plot of back radius of curvature of the lens in $\mathrm{mm}$ units derived from image analysis of Scheimpflug photographs, against age in years. Separate linear regression lines for diabetics and controls. non-diabetics, though the numbers of diabetics in this study were small and it is possible that a moderate to small difference may have been missed.

Animal studies have shown that the lenticular epithelium can be stimulated by a number of biological substances. Mitosis can be reinitiated in the epithelium of hypophysectomised frogs by insulin, growth hormone, prolactin and triiodothyronine. ${ }^{36-38}$ In the rabbit lens insulin, insulin-like growth factors (IGF 1 and 2), and epidermal growth factor (EGF) can stimulate

TABLE 2 Summary of $p$ values from analysis of lens dimensions in early-onset diabetes and controls (clear lenses)

\begin{tabular}{|c|c|c|c|c|c|c|c|}
\hline & Lens & Cortex & Nucleus & $A C Z$ & $A C$ & $F R$ & $B K$ \\
\hline \multicolumn{8}{|c|}{ All subjects $(n=306)$} \\
\hline $\begin{array}{l}\text { Age } \\
\text { Status }\end{array}$ & $<10^{-6}$ & $\begin{array}{l}<10^{-6} \\
<10^{-6}\end{array}$ & $\begin{array}{l}<100 \\
0.00002\end{array}$ & $<10^{-6}$ & $\begin{array}{l}\ll 10^{-0} \\
<10^{-6}\end{array}$ & $\begin{array}{l}\ll 10^{-6} \\
<10^{-6}\end{array}$ & $\begin{array}{l}<10^{-6} \\
<10^{-6}\end{array}$ \\
\hline Age.Sta & 0.00008 & 0.0021 & NS & NS & 0.021 & NS & NS \\
\hline Sex & NS & 0.0010 & 0.00061 & NS & 0.017 & NS & NS \\
\hline \multicolumn{8}{|c|}{ Early-onset diabetes $(n=153)$} \\
\hline Age & $\ll 10^{-6}$ & $\ll 10^{-6}$ & $<10^{-6}$ & NS & $\ll 10^{-6}$ & $\ll 10^{-6}$ & $<10^{-6}$ \\
\hline DŨR & $<10^{-6}$ & 0.000002 & 0.0049 & NS & $<10^{-6}$ & $<10^{-6}$ & 0.00002 \\
\hline Sex & NS & 0.0070 & NS & NS & NS & NS & NS \\
\hline INS & NS & NS & 0.0057 & 0.045 & NS & NS & NS \\
\hline BGR & NS & NS & 0.045 & 0.0032 & NS & 0.047 & NS \\
\hline PLR & NS & NS & NS & 0.016 & NS & NS & 0.034 \\
\hline \multicolumn{8}{|c|}{ Controls $(n=153)$} \\
\hline Age & $\ll<10^{-6}$ & $\ll<10^{-6}$ & 0.00006 & 0.010 & $<10^{-6}$ & $\ll<10^{-6}$ & $<10^{-6}$ \\
\hline Sex & NS & 0.011 & 0.0012 & NS & NS & NS & NS \\
\hline
\end{tabular}

$\mathrm{AC}=$ anterior chamber depth. $\mathrm{ACZ}=$ anterior clear zone thickness of lens. $\mathrm{FR}=$ front radius of curvature of lens. $B K=$ back radius of curvature of lens. STA=diabetic or non-diabetic status. DUR=diabetic duration. INS=daily insulin dose. $B G R=$ background retinopathy.

PLR = proliferative retinopathy.

TABLE 3 Summary of slopes for age and diabetic duration from multiple linear regression analysis of lens dimensions in early-onset diabetes and controls (clear lenses)

\begin{tabular}{|c|c|c|c|c|c|c|}
\hline & Lens & Cortex & Nucleus & $A C$ & $F R$ & $B K$ \\
\hline $\begin{array}{l}\text { Controls }(n=153 \\
\text { Age slope } \\
\text { p }\end{array}$ & $\begin{array}{l}+0.025 \\
\ll 10^{-6}\end{array}$ & $\begin{array}{l}+0.022 \\
\ll<10^{-6}\end{array}$ & $\begin{array}{c}+0.0029 \\
0.00006\end{array}$ & $\begin{array}{l}-0.014 \\
<10^{-6}\end{array}$ & $\begin{array}{l}-0.077 \\
\ll<10^{-6}\end{array}$ & $\begin{array}{l}-0.027 \\
<10^{-6}\end{array}$ \\
\hline $\begin{array}{l}\text { Early-onset diab } \\
\text { DUR Slope } \\
\text { p } \\
\text { Slope ratio } \\
\text { (DUR/age) }\end{array}$ & $\begin{array}{l}e s(n=153) \\
+0.017 \\
<10^{-6}\end{array}$ & $\begin{array}{l}+0.013 \\
0.000002\end{array}$ & $\begin{array}{r}+0.0035 \\
0.0049\end{array}$ & $\begin{array}{l}-0.014 \\
<10^{-6}\end{array}$ & $\begin{array}{l}-0.068 \\
<10^{-6}\end{array}$ & $\begin{array}{c}-0.014 \\
0.00002\end{array}$ \\
\hline
\end{tabular}

$\mathrm{p}=$ Probability $. \mathrm{DUR}=$ diabetic duration $. \mathrm{AC}=$ anterior chamber depth. $\mathrm{FR}=$ front radius of curvature of lens. BK= back radius of curvature of lens. The slopes for age from the control groups were imposed upon the diabetic groups in order to avoid unwanted distortion of the age and duration slopes due to the effects of partially correlated variables. lens epithelial mitosis in serum free culture medium. ${ }^{39}{ }^{40}$ Fibroblast growth factors (basic and acidic FGF) are both mitogenic and capable of inducing changes in cell culture which are characteristic of fibre differentiation in rat lens epithelial explants. ${ }^{41} 42$ Several of these growth factors are known to exist in the ocular tissues. Thus eye-derived growth factors ( 1 and 2$)$ and retina-derived (endothelial cell) growth factors $(\beta$ and $\alpha)$ are synonymous with fibroblast growth factors (basic and acidic), and angiogenic factor derived from the retina (retina-derived endothelial growth factor) may also be synonymous with a fibroblast growth factor, ${ }^{42}$ though this is disputed..$^{434}$ Lentropin, derived from vitreous humour, has been identified as an insulin-like growth factor which is capable of initiating fibre differentiation in lens epithelial explants from chick embryos. ${ }^{45}$ Modulation of the effects of these growth factors by the plasma membrane $\mathrm{Na}^{+} \mathrm{H}^{+}$exchanger (via intracellular $\mathrm{pH})$ may play a part. ${ }^{46}$ The above suggests that there are multiple regulatory peptides capable of influencing the mitotic activity of the lenticular epithelium, some of which are structurally similar to insulin, with insulin itself having mitogenic properties. Insulin can also produce a hypertrophic cellular response without stimulation of DNA synthesis. ${ }^{34}$.

There is general agreement that growth hormone $(\mathrm{GH})$ is raised in human diabetes. ${ }^{47}$ No consensus exists with regard to IGF 1 , however, with levels having been reported which are raised, normal, or reduced in diabetics compared with controls. ${ }^{48}$ Raised IGF 1 has been associated with the existence of retinopathy, ${ }^{49}$ though this association was not found when an adjustment for the presence of proteinuria was made. ${ }^{48}$ In the present work an association between retinopathy and increased anterior clear zone thickness, nuclear size, and steeper curvatures was found (renal status not accounted for). A retina-derived growth factor (which may be raised in eyes with retinopathy) may play a part in this association. Recent work indicates that non-diabetic renal transplant patients have increased anteroposterior lens thickness. ${ }^{50}$

The increased size of the anterior clear zone of the lens in early-onset diabetes is associated in the present study with increased daily insulin dose. Insulin is known to have a mitogenic effect on the lenticular epithelium,,$^{394}$ and it can also induce hypertrophy in an epithelial tissue. ${ }^{34}$ The possibility exists that the above association could be significant in terms of a causal role for isulin in stimulating lens growth. In individual diabetic patients the insulin dose would vary from time to time, so the prevailing dose at the time of lens photography may not represent a composite statement about insulin dose covering the entire duration of the diabetic state. On the other hand the prevailing insulin dose may be more relevant to the thickness of the anterior clear zone. Too high insulin dosage or high pulses of insulin associated with insulin injections may be relevant in this regard. ${ }^{51}$ From the present data there is no way of distinguishing between changes resultant on the effects of 'worse diabetes' (requiring more insulin), and the possible effects of the insulin itself. The association between increased daily 
insulin dose and increased nuclear thickness is difficult to interpret.

Extracellular overhydration of the lens as a whole (unless progressive with years of diabetes) cannot easily explain the powerful effect of duration found in the present study. Simple osmotic events related to the polyol pathway 5253 therefore seem an unlikely explanation. Overhydration at the cellular level, however, remains a possible cause of the biometric changes. Cellular overhydration of metabolically active recently formed fibres only would fit with the 'hypertrophic model', and could satisfactorily explain a duration effect. A number of mechanisms are available by which cellular overhydration could come about. Abnormally functioning membrane pumps might be involved, with damage to $\mathrm{Na}^{+} \mathrm{K}^{+}$ATPase by non-enzymatic glycosylation ${ }^{54}$ or oxidation ${ }^{55}$ possibly playing a role. (Diabetics may be at increased risk of damage by oxidation from autooxidation of monosaccharides ${ }^{5657}$ or depletion of glutathione. ${ }^{5859}$ ) Other membrane pumps could be similarly damaged in the diabetic. Thus, not only $\mathrm{NA}^{+} \mathrm{K}^{+}$ATPase but also $\mathrm{Ca}^{++}$ATPase and the $\mathrm{Na}^{+} \mathrm{H}^{+}$exchanger might be affected. Malfunction of $\mathrm{Na}^{+} \mathrm{K}^{+}$ATPase and the $\mathrm{Na}^{+} \mathrm{H}^{+}$exchanger could affect cellular hydration and fibre size in keeping with the 'hypertrophic model,' while malfunction of the $\mathrm{Na}^{+} \mathrm{H}^{+}$ exchanger could also have an effect (by modulation of growth factors) on the mitotic activity of the epithelium. ${ }^{460}$ The present data do not allow a distinction to be drawn between an abnormality of lens growth and an abnormality of cellular hydration.

The authors are grateful to Dr D Hockaday, Dr J Mann, Dr D Dunger, Mr H Cheng, Mr P Awdry, and Mr A Freedman for allowing their patients to be recruited to this study, and to Dr J Bithell for his statistical advice. This work was supported by Oxford Regional Health Authority NHS Locally Organised Research Grant Number $85 / 19$ and by a British Diabetic Association Research Grant.

1 Weale RA. The aging eye. London: Lewis, 1963

2 Weekers R, Delmarcelle Y, Luyckx-bacus J, et al. Morphological changes of the lens with age and cataract. In: Elliot $\mathrm{K}$, Fitzsimons DW, eds. The human lens in relation to cataract. CIBA foundation symposium 19:1973.

3 Brown NAP. Dating the onset of cataract. Trans Ophthalmol Soc UK 1976; 96: 18-23.

4 Marshall J, Beaconsfield $M$, Rothery S. The anatomy and development of the human lens and zonules. Trans Ophthalmol Soc UK 1982; 102: 423-40.

5 Brown NAP, Sparrow J, Bron AJ. Central compaction in the process of lens growth as indicated by lamellar cataract. $\mathrm{Br} \mathcal{F}$ process of lens growth as indicated

6 Brown NAP. The change in lens curvature with age. Exp Eye Res 1974; 19: 175-83.

7 Huggert $A$. The appearance of the band of disjunction of the lens in diabetes mellitus. Acta Ophthalmol $(K b h) 1953 ; 31$ : 227-34.

8 Brown NAP, Hungerford J. The influence of the size of the lens in ocular disease. Trans Ophthalmol Soc UK 1982;102: 359-63.

9 Caird FI, Hutchinson M, Pirie A. Cataract and diabetes. BrMed f 1964; ii: 665-8.

10 Hiller R, Kahn HA. Senile cataract extraction and diabetes. BrF Ophthalmol 1976; 60: 283-6.

11 Norn MS. Diabetes mellitus and cataracta senilis. Acta Ophthalmol (KGh) 1967; 45: 322-32.

12 Ederer F, Hiller R, Taylor HR. Senile lens changes and diabetes in two population studies. Am $\mathcal{F}$ Ophthalmol 1981; 91: 381-95.

13 Bernth-Petersen P, Bach E. Epidemiologic aspects of cataract surgery. (3) Frequencies of diabetes and glaucoma in a cataract population. Acta Ophthalmol (Kbh) 1983; 61: 406-16.

14 Schwab IR, Dawson CR, Hoshiwara I, Szuter CF, Knowler WC. Incidence of cataract extraction in Pima Indians: diabetes as a risk factor. Arch Ophthalmol 1985; 103: 208-12.

15 Eckerskorn U, Hockwin O, Müller-Breitenkamp R, Chen TT, Knowles W, Dobbs RE. Evaluation of cataract related risk factors using detailed classification systems and multivariate statistical methods. Dev Ophthalmol 1987; 15: 82-91.
16 van Heyningen $\mathrm{R}$, Harding $\mathrm{JJ}$. A case-control study of cataract in Oxfordshire: some risk factors. Br $\mathcal{F}$ Ophthalmol 1988; 72: 804-8.

17 Caird FI, Pirie A, Ramsell TG. Diabetes and the eye. Oxford and Edinburgh: Blackwell, 1969.

18 Vinding T, Nielsen NV. Two cases of acutely developed cataract in diabetes mellitus. Acta Ophthalmol $(K b h)$ 1984; 62: 373-7.

19 Brown CA, Burman D. Transient cataracts in a diabetic child with hyperosmolar coma. Brf Ophthalmol 1973; 57: 429-33.

20 Jarrett JR. Diabetes mellitus. (Series in clinical epidemiology.) London, Sidney: Croom Helm, 1986.

21 WHO Study Group. Diabetes mellitus. WHO Techn Rep Ser 727. Geneva: WHO, 1985.

22 Brown NAP, Tripathi R. The loss of the anterior clear zone of the lens: prognostic significance in cataract formation. Trans the lens: prognostic significance in cat
Ophthalmol Soc UK 1974; 94: 29-45.

23 Perkins ES. Lens Thickness in early cataract. Br $\mathcal{F}$ Ophthalmol 1988; 72: 348-53.

24 Sparrow JM, Bron AJ, Brown NAP, Ayliffe W, Hill AR. The Oxford clinical cataract classification and grading system. Int Ophthalmol 1986; 9: 207-25.

25 Brown NAP. Slit-image photography. Trans Ophthalmol Soc UK 1969; 89: 397-408.

26 Brown NAP. An advanced slit image camera. Brf Ophthalmol 1972; 56: 624-31.

27 Brown NAP. Quantitative slit-image photography of the lens. Trans Ophthalmol Soc UK 1972; 92: 303-17.

28 Sparrow JM. The lens in diabetes. D Phil Thesis. Linacre College, University of Oxford: 1988.

29 Rosner B. Statistical methods in ophthalmology: an adjustment for the intraclass correlation between eyes. Biometrics 1982, 38: $105-14$

30 Ray WA, O'Day DM, Head WS, Robinson R. Statistical analysis for experimental models of ocular disease: continuous response measures. Curr Eye Res 1985; 4:585-97.

31 Ray WA, O'Day DM. Statistical analysis of multi-eye data in ophthalmic research. Invest Ophthalmol Vis Sci 1985; 26: 1186-8.

32 Goldmann $\mathrm{H}$. Senile changes of the lens and vitreous. $A m \mathcal{F}$ Ophthalmol 1964; 57: 1-13.

33 Niesel $P$. Visible changes of the lens with age. Trans Ophthalmol Soc UK 1982; 102: 327-30.

34 Fine L. The biology of renal hypertrophy. Kidney Int 1986; 29 : 619-34.

35 Brown NAP, Bron AJ, Sparrow JM. An estimate of the size and shape of the human lens fibre in vivo. $\mathrm{Br} \mathcal{F}$ Ophthalmol 1987; 71: $916-22$.

36 Reddan JR, Harding CV, Rothstein H, Crotty MW, Lee P, Freeman $\mathrm{N}$. Stimulation of mitosis in the vertebrate lens in the presence of insulin. Ophthalmic Res 1972; 3: 65-81.

37 Wainwright N, Hayden J, Rothstein $\mathrm{H}$. Total disappearance of cell proliferation in the lens of a hypophysectomized animal. Cytobios 1978; 23: 79-92.

38 Rothstein H, Van Wyk JJ, Hayden JH, Weinsider A, Somatomedin C. Somatomedin C: Restoration in vivo of cycle traverse in $\mathrm{G} 0 / \mathrm{Gl}$ Blocked cells of hypophysectomized animals. Science 1980; 208: 410-2

39 Reddan JR, Dziedzic DC. Insulin-like growth factors, IGF-1, IGF-2 and somatomedin $C$ trigger cell proliferation in mammalian epithelial cells cultured in a serum-free medium. Exp Cell Res 1982; 142: 293-300.

40 Reddan JR, Wilson-Dziedzic D. Insulin growth factor and epidermal growth factor trigger mitosis in lenses cultured in a serum-free medium. Invest Ophthalmol Vis Sci 1983; 24 : 409-16.

41 McAvoy JW, Fernon VTP. Neural retinas promote cell division and fibre differentiation in lens epithelial explants. division and fibre differentiation

42 Chamberlain CG, McAvoy JW. Evidence that fibroblast growth factor promotes lens fibre differentiation. Curr Eye Res 1987; 6: 1165-8.

43 Elstow SF, Schor AM, Weiss JB. Bovine retinal angiogenesis factor is a small molecule (molecular mass $<600$ ). Invest Ophthalmol Vis Sci 1985; 26: 74-9.

44 Taylor CM, Weiss JB, Kissun RD, Garner A. Effect of oxygen tension on the quantities of procollagenase-activating angiogenic factor present in the developing kitten retina. $\mathrm{Br} F$ genic factor present in the
Ophthalmol 1986; 70: 162-5.

45 Beebe DC, Silver MH, Belcher KS, van Wyk JJ, Svoboda $M E$. Lentropin, a protein that controls lens fibre formation, is related functionally and immunologically to the insulin like growth factors. Proc Natl Acad Sci USA 1986; 84: 2327-31.

46 Mahnensmith RL, Aronson PS. The plasma membrane sodium-hydrogen exchanger and its role in physiological and pathophysiological processes. Circulation Res 1985; 56: 773-88.

47 Holly JMP, Amiel SA, Sandhu RR, Rees LH, Wass JA. The role of growth hormone in diabetes mellitus. $\mathcal{F}$ Endocrino 1988; 118: 353-64.

48 Hyer SL, Sharp PS, Brooks RA, Burrin JM, Kohner EM Serum IGF-1 concentration in diabetic retinopathy. Diabetic Medicine 1988; 5: 356-60.

49 Merimee TJ, Zapf J, Froesch ER. Insulin like growth factors. Studies in diabetics with and without retinopathy. $N E n g l \mathcal{F}$ Med 1983; 309: 527-30.

50 Shun-Shin GA, Bron AJ, Ratcliffe P, Sparrow JM, Brown NAP. The lens in renal transplantation. $\mathrm{Br} \mathcal{F}$ Ophthalmol $1990 ; 74: 267-71$. 
51 Rizza RA, Gerich JE, Haymond M, et al. Control of blood sugar in insulin-dependent diabetes: comparison of an artificial endocrine pancreas, continuous subcutaneous insulin infusion, and intensified conventional insulin therapy.

52 van Heyningen $R$. Formation of polyols by the lens of the rat with sugar cataracts. Nature 1959; 164: 194-5.

53 Kinoshita JH. Mechanisms initiating cataract formation. Invest Ophthalmol Vis Sci 1974; 13: 713-24.

54 Garner MH, Spector A. ATP hydrolysis kinetics in Na, K-ATPase in cataract. Exp Eye Res 1986; 42: 339-48.

55 Spector A. Exidation and cataract. In: Nugent J, Whelan J, eds. Human cataract formation. CIBA foundation symposium 106: $1984: 48-64$
56 Crabbe JC. Discussion: Diabetic and galactosaemic cataracts. In: Nugent J, Whelan J, eds. Human cataract formation. In: Nugent $\mathrm{J}$, Whelan $\mathrm{J}$, eds. Human cataract

57 Wolff SP, Crabbe MJ. Low apparent aldose reductase activity produced by monosaccharide autoxidation. Biochem $\mathcal{F} 1985$; 226: 625-30.

58 Varma SD, Richards RD. Etiology of cataracts in diabetics. Int Ophthalmol Clin 1984; 24: 93-110.

59 Kador PF, Kinoshita JH. Diabetic and galactosaemic cataracts. In: Nugent J, Whelan J, eds. Human cataract formation. CIBA foundation symposium 106: 1984: 110-23.

60 Duncan G. Role of membranes in controlling ion and water movements in the lens. In: Elliot $\mathrm{K}$, Fitzsimons DW, eds. The human lens in relation to cataract. CIBA foundation symposium 19: 1973: 99-116. 